Impact of Terlipressin Infusion during and after

\title{
Live Donor Liver Transplantation
}

on Incidence of Acute Kidney Injury.

A Randomized Controlled Trial

Abdel Raouf M. ${ }^{1}$, Abou Elenain K. ${ }^{2}$, Al Sebaey A. ${ }^{1}$, Said H. ${ }^{1}$, Afifi M. ${ }^{2}$, Yassen K. ${ }^{1}$

${ }^{1}$ National Liver Institute, Menoufiya University, Dept of Anaesthesiology, Shebin El Kom, Egypt.

${ }^{2}$ Faculty of Medicine, Menoufiya University, Dept of Anaesthesiology, Shebin El Kom, Egypt

Table 1: incidence of AKI and Serum NGAL levels in the studied groups

\begin{tabular}{|c|c|c|c|}
\hline & Control & Terlipresin & $\mathbf{P}$ \\
\hline \multicolumn{4}{|l|}{ AKI } \\
\hline - No & $14(56.0 \%)$ & $13(52.0 \%)$ & 0.777 \\
\hline - Yes & $11(44.0 \%)$ & $12(48.0 \%)$ & \\
\hline Pearson Chi-Square & \multicolumn{2}{|c|}{$X^{2}=0.081$} & \\
\hline NGAL(ng/ml) & & & \\
\hline Preoperative & $57.31 \pm 27$ & $74.06 \pm 74$ & 0.10 \\
\hline 2 hr Post-reperfusion & $108.04 \pm 72$ & $115.28 \pm 97$ & 0.76 \\
\hline $24 \mathrm{hr}$ post-reperfusion & $93.10 \pm 80$ & $112.50 \pm 98$ & 0.44 \\
\hline ANOVA & 9.51 & 4.66 & \\
\hline$p$ value & $0.000^{* *}$ & $0.021^{* *}$ & \\
\hline
\end{tabular}

\section{Background and Goal of Work:}

- Acute kidney injury (AKI) with liver transplantation is not uncommon. Impact of Terlipressin infusion on $\mathrm{AKI}$, haemodynamics (systemic and hepatic) and serum concentration of Neutrophil Gelatinase Associated Lipocalin (NGAL) was studied

\section{Methods:}

- A double-blinded prospective randomized controlled trial. (NCT02059460, USA). After Local ethics committee approval and informed consent, 55 recipients were enrolled (5 excluded). Terlipressin (T), $(n=25)$ vs Controls (C), $(n=25)$. Intra and postoperative infusion of $T$ was administrated at a rate of $1-4 \mu \mathrm{g} / \mathrm{kg} / \mathrm{h}$ for 5 days. Norepinephrine was used to maintain mean arterial pressure (MAP) $>65 \mathrm{mmHg}$. Haemodynamic management and fluids administration were guided by TED intra-operatively. Renal functions, urine output, liver enzymes, peak portal vein blood flow velocity (PPV) and hepatic artery resistive index (HARI) were recorded. Enzyme linked immunosorbent assay (ELISA Antibody shop, Denmark) was used for NGAL measurement in serum.

\section{Results:}

- Mainly $96 \%$ of $T$ and $76 \%$ of C were Hepatitis C positive. Age, sex, MELD score and renal functions were comparable. Postoperative AKI incidence and NGAL concentrations were not significantly different between $\mathrm{T}$ and $\mathrm{C}$ groups (44\% vs $48 \%, P=0.777$ and $112.5 \pm 9$ vs $93.1+8 \mathrm{ng} / \mathrm{ml}, P=0.44$, respectively), but intraoperative NGAL in both groups increased significantly $2 \mathrm{hr}$ post reperfusion $(P<0.05)$. NGAL readings at different measuring points showed no significant difference between recipients developing AKI $(n=23)$ and others with no AKI $(n=27),(p>0.05)$. Receiver operator characteristic (ROC) analysis demonstrated that NGAL could not significantly discriminate between $A K I$ and non-AKI ( $p>0.05)$. MAP was maintained in both groups with less SVR fluctuations observed with $T$ and hence a reduced need for norepinephrine. Median [IQR] norepinephrine consumption in T vs $C(8[0-12]$ vs $12[8-20] \mathrm{mg}, P=0.04$, respectively). Lactate, liver enzymes, PPV and HARI of the graft were not affected by $T$ at any stage, $(P>0.05)$
Table 2: Serum NGAL level (ng/ml) in (AKI) and none AKI groups

\begin{tabular}{|l|c|c|c|}
\hline & \multicolumn{1}{|c|}{$\begin{array}{c}\text { Non-AKI } \\
(\mathrm{n}=27)\end{array}$} & $\begin{array}{c}\text { AKI } \\
(\mathrm{n}=23)\end{array}$ & \\
\hline NGAL preoperative & & \\
\hline mean \pm SD & $52.31 \pm 31$ & $70.51 \pm 77$ & 0.79 \\
\hline median(IQR) & $42[30.9-67.5]$ & $42[31.2-69]$ & \\
\hline NGAL 2h post-reperfusion & & \\
\hline mean \pm SD & $90.4 \pm 55$ & $136 \pm 106$ & 0.13 \\
\hline median(IQR) & $72.6[45-127]$ & $129.1[56-162]$ & \\
\hline NGAL 24h post-reperfusion & & \\
\hline mean \pm SD & $92 \pm 78.3$ & $115 \pm 101$ & 0.59 \\
\hline median(IQR) & $63.9[42-117]$ & $76.5[38.7-163]$ & \\
\hline
\end{tabular}

\section{Conclusion}

- Terlipressin infusion did not provide renal protection for the recipients in this trial. Observed reduction in intraoperative SVR fluctuations with $T$ helped to maintain MAP with less catecholamines, this effect need to be studied further. Similarly, intraoperative serum NGAL did not show evidence for its possible role to discriminate $\mathrm{AKI}$ developing recipients from non-AKI. Terlipressin did not affect the graft hepatic circulation in this study.

\section{Reference:}

- Cheng CW, Chen YC, Chang $\mathrm{CH}$, Yu HP, Lin CC, Yang MW, Lee WC, Chang CJ: The ratio of plasma neutrophil gelatinase-associated lipocalin predicts acute kidney injury in patients undergoing liver transplantation. Transplant Proc 2012; 44: 776-9. 